\title{
LA CALIDAD DE LA EDUCACIÓN EN AGUASCALIENTES DISEÑO DE UN SISTEMA DE MONITOREO
}

FELIPE MARTíNEZ RIZO, la calidad de la educación en Aguascalientes. Diseño de un sistema de monitoreo, Aguascalientes, UAA, 1996.

(r)

domo lo señala el propio autor, la historia que hay detrás de este libro es larga, y en sentido amplio se remonta hasta los inicios de la acción organizada y sistemática de la investigación educativa en la Universidad Autónoma de Aguascalientes. Obviamente hay acciones y proyectos concretos que constituyen antecedentes cercanos del trabajo específico que ahora nos ocupa, todos los cuales se enmarcan en un contexto de estrecha vinculación con el sector educativo estatal.

Para el autor, la riqueza de la retroalimentación es algo innegable; por ello, en la elaboración de este trabajo buscó expresamente la opinión y el juicio de expertos en la materia, consciente de que ello contribuiría de manera fundamental a enriquecer su propuesta. De esta suerte, diferentes versiones del documento se sometieron a ese proceso en dos ocasiones; desde luego, muchas de las observaciones y sugerencias recibidas fueron retomadas y forman parte ya del texto que nos ocupa; sin embargo, no deja de ser relevante abordar esta reseña desde esa perspectiva y destacar de lo que se discutió y aportó, los siguientes puntos de polémica y/o de particular interés, algunos de ellos sugerentes para la continuación de una línea de investigación que bajo el aliento de Felipe Martínez Rizo ha cobrado especial importancia dentro del Programa de Investigaciones Educativas de la Universidad:

$1^{\circ}$ Más allá de la mera cuestión nominal, ¿cuál debería ser el término más apropiado para nombrar al sistema? ¿Monitoreo o evaluación? Cada uno de ellos supone sin duda perspectivas conceptuales diferentes. Para algunos expertos el 
término monitoreo es más limitado, sugiere casi la mera observación de los fenómenos, dejando fuera la explicación, la valoración y la toma de decisiones, aspectos que la evaluación sí englobaría; para otros, el término monitoreo da realce a la idea de seguimiento permanente, mientras que el de evaluación podría sugerir más bien un acercamiento limitado a los resultados - de diverso tipo- del sistema educativo.

Para el autor, el hecho de que los sistemas más importantes y completos a nivel mundial se denominen como "sistemas de monitoreo" es sugerente de una mayor aceptación y carga semántica del término. De cualquier forma, aborda expresamente el asunto en la obra y establece las razones para preferir este término: el sistema de monitoreo propuesto no pone su énfasis en la evaluación propiamente dicha; pretende más bien constituirse en un medio que, bien concebido y funcionando adecuadamente, permita a los responsables del sistema educativo, realizar evaluaciones bien fundamentadas y oportunas. De ahí que sea importante, su aplicación permanente. Por otro lado,

la distinción terminológica permite también enfatizar la diferencia de los roles del personal técnico y de los tomadores de decisiones. El manejo de un sistema de monitoreo es una ta- rea esencialmente técnica. La evaluación propiamente dicha, en cambio, constituye un aspecto de la toma de decisiones, que tiene que ser competencia de quienes tengan la autoridad legítima.

$2^{\circ}$ La riqueza del modelo no puede ponerse en duda, pero una vez que éste aporta información, ¿qué debe seguirse en lo que respecta a la toma de decisiones? Si varias áreas aparecen como problemáticas, ¿̨a qué debe ponerse prioridad? Por ejemplo, si en un indicador de aprendizajes se observa un nivel muy bajo de los alumnos, qué debe atenderse, ¿la actualización de los maestros? ¿El diseño de los materiales? ... El sistema -se decía-, debe analizarse también desde la perspectiva de su utilidad para la toma de decisiones; como se ve, aún cuando se reconozca el carácter esencialmente técnico del sistema de monitoreo, subsisten las preocupaciones en torno a su relación con las esferas de la práctica y la política educativa.

Sin duda que éste es un punto de difícil solución: ¿̨hasta dónde llega el alcance de una propuesta diseñada más desde la óptica de la investigación que desde la relativa a la toma de decisiones? ¿Cuál es, en última instancia, la utilidad práctica del quehacer investigativo? Ante este cuestionamiento, el autor sostiene su convicción de que no son aceptables pos- 
turas extremas: la investigación no lo va a resolver todo, pero tampoco puede decirse que no sirve para nada.

Por otro lado, si se acepta que para la orientación o reorientación de las políticas y prácticas educativos es válida la secuencia descripción-explicación-toma de decisiones, lo que un sistema de monitoreo confiable puede aportar es un conjunto de buenas descripciones; si además -como lo sugiere el autor-, a la implementación del sistema le acompaña un esfuerzo deliberado y sistemático por hacer investigación, entonces se puede aspirar a lograr la explicación y, en consecuencia, aportar para la toma de decisiones una base sólida de la cual partir. Ello no implicará que ante dilemas muy específicos las opciones de acción para los tomadores de decisiones sean nítidas. Tomar una decisión supone, inevitablemente, hacer un compromiso, quizás privilegiar algo en detrimento de otra cosa. Piénsese, si no, en la tensión implícita en los diferentes componentes y elementos del concepto de calidad; como lo señala el autor, las diversas dimensiones del concepto de calidad deben jerarquizarse e integrarse en una combinación única para cada caso o situación en la que deban aplicarse ya que, por su naturaleza misma, no es posible optimizarlas todas simultáneamente.
Con todo, la definición misma del sistema, los indicadores que propone, dado que están planteados desde una concepción explícita de calidad, orienta en la esfera de la política y la toma de decisiones, es decir, orienta hacia dónde debe de ir la calidad de un sistema educativo.

$3^{\circ}$ Ahora bien, ligado a lo anterior, el concepto de calidad que subyace al modelo tiene para los expertos algunas limitaciones: por un lado, el hecho de que privilegia lo macro, es decir, la perspectiva de corte más global, ante lo cual surge la pregunta de si no será necesaria otra definición de calidad al nivel micro, es decir, al nivel de la escuela; por otro lado, es también importante reconocer que los conceptos pueden ir transformándose, enriqueciéndose y adaptándose a nuevas realidades, de suerte de ser más inclusivos. Sobre este punto, Pablo Latapí sugería considerar como un elemento constitutivo de la calidad -tanto en lo individual como en lo institucional-, la capacidad de seguir creciendo, de aprender de la propia experiencia; si éste es un rasgo que efectivamente se puede incorporar dentro del concepto de calidad educativa, entonces el sistema de monitoreo debe tener también la capacidad de medirlo.

Esta cuestión apunta con claridad una de las vetas de desarrollo que se derivan de la obra que nos ocupa. Lo hace tam- 
bién, el punto que enseguida se presenta, relacionado con los procesos que se seguirían de la implementación del sistema de monitoreo propuesto.

$4^{\circ} \mathrm{Si}$ bien el sistema supone ya una cierta operacionalización del concepto de calidad sostenido por el autor, es preciso reconocer que se trata aún de una propuesta más bien conceptual; como el autor lo señala en la conclusión de la obra, es todavía necesario desarrollar cuatro componentes importantes del modelo: el diseño de las metodologías de recabación de información del sistema, el diseño de la aplicación de los procesos del sistema, el diseño del análisis de la información evaluativa del sistema y el diseño del uso de la información evaluativa.

Cada una de las tareas mencionadas requiere un esfuerzo de mayor o menor grado de complejidad pero que, sin duda, deberá ser desarrollado sistemáticamente por personal calificado. Tan sólo en lo que se refiere al diseño de las metodologías de obtención de información -lo que en realidad supone la definición de metodologías y enfoques de investigación adecuados para cada componente del sistema-, el terreno es aún muy vasto, aunque por demás atractivo. Si bien hay indicadores que por su naturaleza misma son más facilmente asequibles -se podría incluso decir que se cuenta ya con ellos-, otros requieren aún de un proceso gradual de construcción. Piénsese, por ejemplo, en los mecanismos para evaluar el funcionamiento de los centros escolares, tratando de atender a los procesos de carácter menos objetivo o evidente que tienen lugar a su interior, tales como la cohesión del grupo de maestros, el liderazgo del director, la oportunidad efectiva de aprendizaje para los educandos, la existencia de un ambiente ordenado y productivo propicio para la enseñanzaaprendizaje; o bien, en los mecanismos para recabar información sobre los niveles de aprendizaje logrados por los educandos, cuyo desarrollo, si se aspira a lograr los exigentes estándares de calidad que han establecido instituciones de prestigio mundial en la materia, requiere de una gran capacidad técnica.

Dadas estas condicionantes, el autor reconoce que no todos los indicadores que constituyen el sistema de monitoreo propuesto podrán obtenerse desde los primeros momentos de su aplicación. Sugiere entonces centrar la atención en los que satisfagan mejor los criterios de consistencia técnica, disponibilidad, utilidad e interés.

En particular, los dos últimos criterios nos remiten a la cuestión planteada en el segundo de los puntos enumerados, esto es, la vinculación del sistema de monito- 
reo con la toma de decisiones. Sin duda, el sistema puede aportar información a más corto plazo, si se trabaja desde la perspectiva de la disponibilidad; sin embargo, si se establecen como criterios prioritarios los de "utilidad" e "interés", entonces se privilegiarían aquellos indicadores que, se refieren a variables importantes y, de preferencia, de las llamadas alterables, puesto que la información que proporcionan puede llevar más fácilmente a acciones de mejoramiento (utilidad), o bien aquellos indicadores que más probabilidades tengan de llamar la atención de los actores, las autoridades y la sociedad sobre aspectos importantes del sistema educativo (interés).

Así, la cobertura del modelo es susceptible de una redefinición constante, en la medida en que se vayan aplicando los diferentes criterios mencionados, y en la medida también que se vaya logrando avanzar en el proceso de construcción de los mismos indicadores.

Indudablemente, una obra como la que nos ofrece Felipe Martínez Rizo puede suscitar muchas más reflexiones y tomas de postura; se puede estar o no de acuerdo con la visión que nos ofrece el autor para el mejoramiento de la calidad educativa; lo que no se puede negar es que se trata de una propuesta sólida y bien fundamentada, valiosa por lo que ya ofrece, pero quizá aún más por la riqueza de líneas de reflexión y trabajo que se desprenden de ella. Si el reclamo de nuestros tiempos es la búsqueda de la calidad, la obra tiene destinatarios concretos a los cuales interpelar; unos, los investigadores dedicados al complejo y fascinante campo de la evaluación educativa y de la evaluación de la calidad en particular, a quienes ofrece pautas concretas para el desarrollo de acciones específicas de investigación, desde distintos enfoques y perspectivas metodológicas; otros, los actores del sistema educativo, sean prácticos o tomadores de decisiones, para quienes la información que el sistema de monitoreo puede aportar debería ser un insumo básico para avanzar en la dirección de lograr un mejor nivel de calidad educativa, ello siempre y cuando se reconozca y acepte el carácter dinámico del concepto. Mientras este sistema consolida su operación, la obra misma invita ya a pensar, a reflexionar y a diagnosticar desde el nivel del aula hasta el nivel más amplio y complejo del sistema educativo estatal en su conjunto, la realidad de nuestra situación actual y la distancia respecto a una situación cualitativamente mejor.

Guadalupe Ruiz Cuéllar DEPARTAMENTO DE EDUCACION/UAA 
